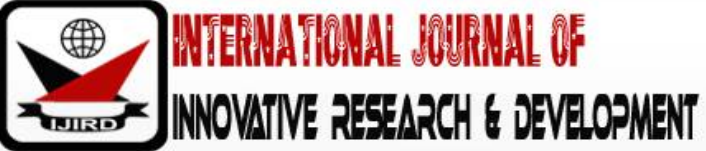

ISSN 2278 - 0211 (Online)

\section{Identification and Quantification of Organophosphate and Carbamate Pesticide Residues in Tomatoes, Carrots, Sorrel and Spinachusing the Quechers Method and Detection by GC-MS}

\begin{tabular}{|c|}
\hline Suleiman Fanika \\
Lecturer, Department of Chemistry, Federal College of Education, Kontagora, Nigeria \\
A.A. Nuhu \\
Lecturer, Department of Chemistry, Ahmadu Bello University, Zaria, Kaduna, Nigeria \\
K.I. Omoniyi \\
Lecturer, Department of Chemistry, Ahmadu Bello University, Zaria, Kaduna, Nigeria \\
Z.I. Yashim \\
Lecturer, Department of Chemistry, Ahmadu Bello University, Zaria, Kaduna, Nigeria \\
Sani Uba \\
Lecturer, Department of Chemistry, Ahmadu Bello University, Zaria, Kaduna, Nigeria
\end{tabular}

\begin{abstract}
:
The Concentrations of organ phosphorus and carbamate pesticide residues were analysed in spinach, tomatoes, carrots and sorrel grown at Dagachi farming areas along River Galma of Zaria in Kaduna State, Nigeria. Samples collection and preparationwere carried out using standard procedures. The concentrations of all the pesticides in the samples were analysed using quick easy cheap effective rugged and safe (QuEChERS) multi- residue extraction and clean up techniques, followed by gas chromatography - mass spectrometry (GC - MS) method of analysis. The most commonly detected organ phosphorus pesticide residues in the entire sample analysed are dichlorvos, mevinfos, diazinon, malathion, chlorpyrifos, ethion, isofenphos and azinphos-methyl. The detected carbamates are the carbaryl and carbofenthion. The linearity ( $\mathrm{r} 2 \geq$ 0.9999 ) for the pesticides was good over the concentration range from $0.05-1.00 \mathrm{ppm}$. The results of the detected organ phosphorus in the samples show that, malathion presents the highest value in carrot with value of $0.522 \mathrm{mg} / \mathrm{kg}$ and lowest value of azinphos- methyl in both carrot and spinach with value of $0.006 \mathrm{mg} / \mathrm{kg}$. Also, chlorpyrifos, $0.099 \mathrm{mg} / \mathrm{kg}$, $0.274 \mathrm{mg} / \mathrm{kg}, 0.122 \mathrm{mg} / \mathrm{kg}$ in spinach, carrot, and sorrel respectively detected were also very high. Other detected organ phosphorus was within the MRLs in all the samples anaysed. However, other organ phosphorus pesticides were detected at a very low concentration. Carbaryl were detected in tomatoes, carrot and sorrel samples with a value of $0.003 \mathrm{mg} / \mathrm{kg}$, $0.003 \mathrm{mg} / \mathrm{kg}$ and $0.002 \mathrm{mg} / \mathrm{kg}$ respectively. The concentrations of all the organophosphorus pesticides in the samples in this research work were observed to be at alarming levels, much higher than the maximum residue limits(MRLs) by the Codex 2009 (WHO and FAO). Therefore, to reduce this risk, sensitization of farmers to better pesticide safety practices and the need for continuous pesticide residue monitoring is highly recommended. Finally, there is a need for the relevant agency to strictly control the importation, sale, use and disposal of these toxic chemicals.
\end{abstract}

Keywords: Organophophorus, Carbamates, Pesticide Residues, vegetables, fruits, QuChERS, cleanup and GC-MS

\section{Introduction}

Pesticides are agrochemicals formulated to combat the attack of pests on agricultural crops. Pests are disease causing organisms that use plants as their source of food. Pesticides have helped to increase crop production by controlling the pests that destroy the crops. Pesticides are widely used in agriculture to increase the yield, improve the quality, and extend the storage life of food crops (Fernandea-Alba and Garcia-Reyes, 2008). Pesticides are also used worldwide to protect crops before and after harvest in agriculture, gardening, homes and soil treatment. Varieties of pesticides are used in current agricultural practices to manage pests and infections that spoil crops (Conacher and Mes, 1993). The controlled pesticides used in agriculture will not affect the environment, whereas uncontrolled pesticide use will cause adverse impacts on the environment such as water, soil and air which cause unbalance in ecosystem. However, some of the pesticides have carcinogenic, tetratogenic, mutogenic, neuro-toxic effects as well as alterations of reproductive processes (Al- Saleh, 1994). Pesticides are classified based on target organisms, chemical structure, and physical state and are available in concentrated liquid or powder form. Various familiar classes of pesticides are herbicides, insecticides, rodenticides, biopesticides and weedicides (Cheng and Bersamira 1994; Gilden et al., 2010) . 
Pesticide residue refers to the pesticides that remain on or in food after they are applied to food crops (Walter, 2009). The maximum allowable levels of these residues in foods are often stipulated by regulatory bodies in many countries. Exposure of the general population to these residues most commonly occurs through consumption of treated food sources, or being in close contact to areas treated with pesticides such as farms or lawns. Many of these chemical residues, especially derivatives of chlorinated pesticides, the organochlorines, exhibit bioaccumulation which could build-up to harmful levels in the body of organisms as well as in the environment (Walter, 2009). Indeed, organochlorine pesticides have been replaced by organonitrogen and organophosphorus pesticides. Organophosphorus Pesticides (OPPs) were introduced at the end of 1930s as the second-generation synthetic pesticides with characteristics of broad spectrum, high efficiency, many varieties and short residual toxicity period. In general, they are easily break down and less persistence than organochlorines (Van Emden, 1989). The basic structure of organophosphorus pesticides consists of ester or thiol derivatives of phosphoric, phosphonic or phosphoramidic acids. Insecticides and Nematicides are carbamates (derivatives of carbamic acid) which were introduced in 1956 with the compound carbaryl. These groups of insecticides, nematicides such as aldicarbs, benomyl, and carbofuran are more persistent than the organophosphates, highly toxic to man. Fungicides such as maneb and mencozeb are under carbamates and are not acutely toxic (Van Emden, 1989). Basically, organophosphorus and carbamate pesticides exert their toxic action by inhibiting the enzyme acetylcholinesterase (AChE). This enzyme is responsible for the hydrolysis of acetylcholine (ACh), a neurotransmitter that conducts nerve impulses across neuromuscular junctions in the nervous system of vertebrates as well as insects. Inhibition of this enzyme causes accumulation of ACh leading to generalized cholinergic action and resulting in rapid, uncontrolled twitching of voluntary muscles which eventually leads to paralysis, respiratory failure and death (Podolska and Napierska, 2006). AchE inhibition by organophosphates is generally irreversible while inhibition by carbamates is reversible. Hence, carbamates are less toxic than organophosphorus compounds. Human exposure to both groups of compounds can be monitored by determining erythrocyte and plasma cholinesterase activity (Guilhermino et al.,2004).Therefore, these synthetic pesticides are mostly persistent to degradation, may remain in fruits and vegetables and cause health hazards to the consumers. So, the aim of this study was to qualify and quantify the presence of OPPs and carbamates pesticide residues in tomatoes, carrots, sorrel and spinach grown along River Galma at Dagachi area of Zaria, Kaduna state, Nigeria, and the analysis was by simple gas chromatographic techniques, usually gas chromatography equipped with mass spectrometry.

\section{Materials and Methods}

\subsection{Chemicals/ Reagents}

Certified reference standards of all the test pesticides of $98 \%$ purity were purchased, Ethyl acetate, Acetonitrile, Methanol, Distilled water, Primary secondary amine (PSA, $40 \mathrm{~cm}$ ) (Bondesil) sorbent, Anhydrous sodium sulphate, Magnesium sulphate, Methanol, Hexane, Sodium chloride, Acetic acid, Sodium acetate, Triphenyl phosphate

\subsection{Apparatus}

SHIMADZU GC/ MS ,High speed homogenizer, Centrifuge machine, Blender, Microcentrifuge, Centrifuge tubes, Volumetric flash, Measuring cylinders, Beakers, Micro pipette or Automatic pipettes, Injection vials, 1, $5 \mathrm{ml}$ suitable for GC and LC auto-sampler, Powered funnel to fill to the openings of the centrifuge tubes, PTFE Screwcap (polytetrafluorethylene, PTFE), Vortex mixer.

\subsection{Quality Assurance}

Analytical reagent grade (Analar) chemicals and distilled water was used throughout the work. All glassware and plastic containers were washed with detergent, $20 \%$ nitric acid and then rinsed with tap water and finally with distil water then allowed to dry.

\subsection{Sample Collection}

Samples of vegetables and fruits was collected from farm areas along River Galma in Zaria in plastic bags and kept refrigerated before analysis. Thereafter, the fresh samples were made into small pieces and homogenised with a household mill equipped with stainless steel knives, and finely ground in a high-speed blender.

\subsection{Sampling \\ Samples was taken at five (5) random points (quadrant approach) at each farm land and mixed to constitute a composite of $1 \mathrm{~kg}$ in plastic bags and immediately transported to the laboratory and kept refrigerated before analysis.}

\subsection{Preparation of Standard Solution / Calibration Curves}

Stock solutions were prepared containing $1000 \mathrm{mgdm}^{-3}$ of each compound to be investigated by accurately weighing $10 \mathrm{mg}( \pm 0.01 \mathrm{mg})$ of each analyte in volumetric flasks and dissolving in $10 \mathrm{~cm}^{3}$ of methanol or acetonitrile contained in a beaker. These would be stored in dark vials in a refrigerator at $4{ }^{\circ} \mathrm{C}$. Working standards were also prepared by serial dilutions. Final concentration (in acetonitrile) of $0.05,0.1,0.25,0.5$, and $1.0 \mathrm{mg} \mathrm{dm}^{-3}$ for each analyte was prepared. Standard solutions of the pesticides were run on GC/ MS under the set chromatographic conditions and mean peak areas were plotted against concentrations to obtain calibration curves of individual pesticides. The calibration curves for some of the pesticides are shown in Figures below: 


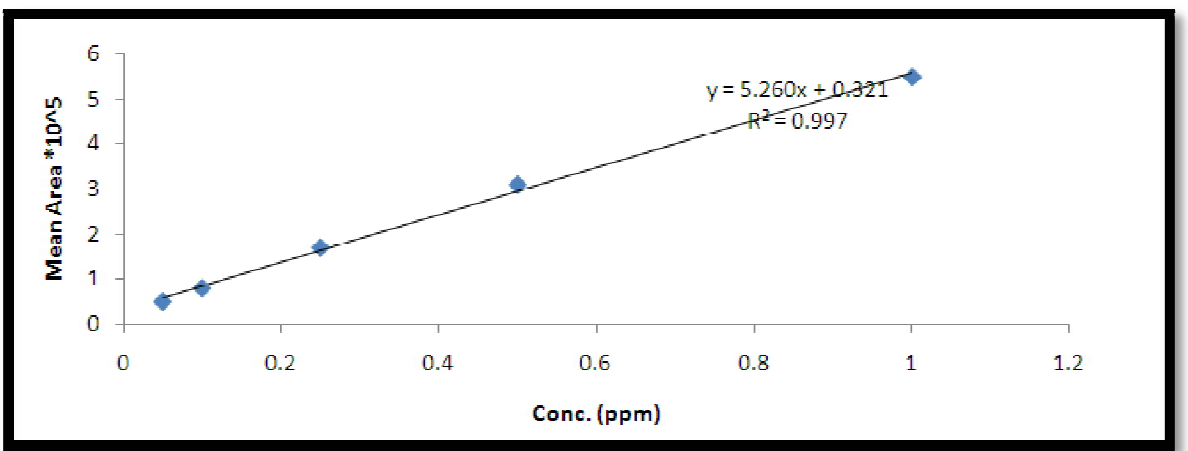

Figure 1: Calibration Curve for Dichlorvos Standard

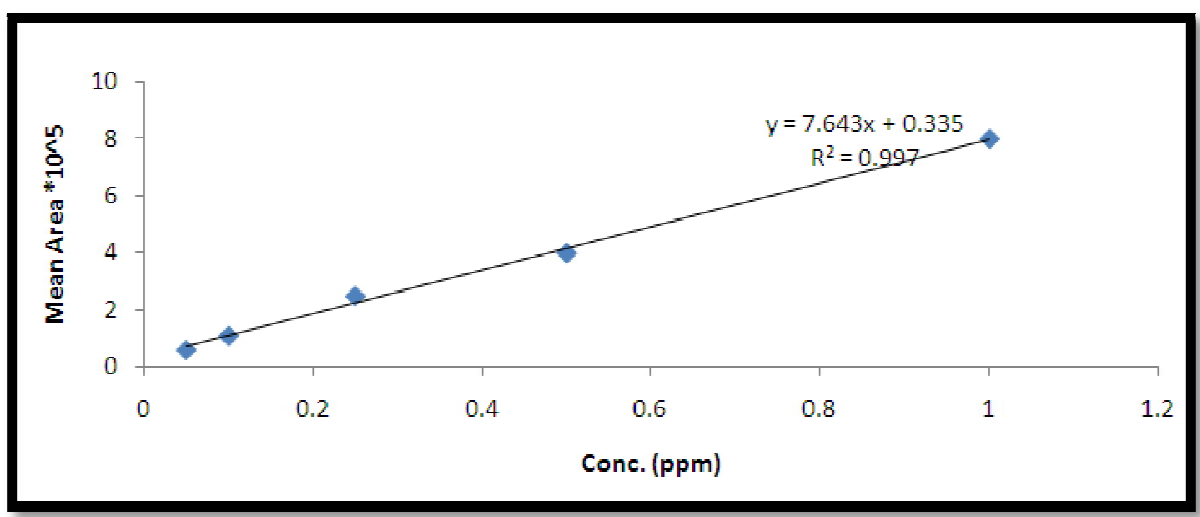

Figure 2: Calibration Curve for Mevinfos Standard

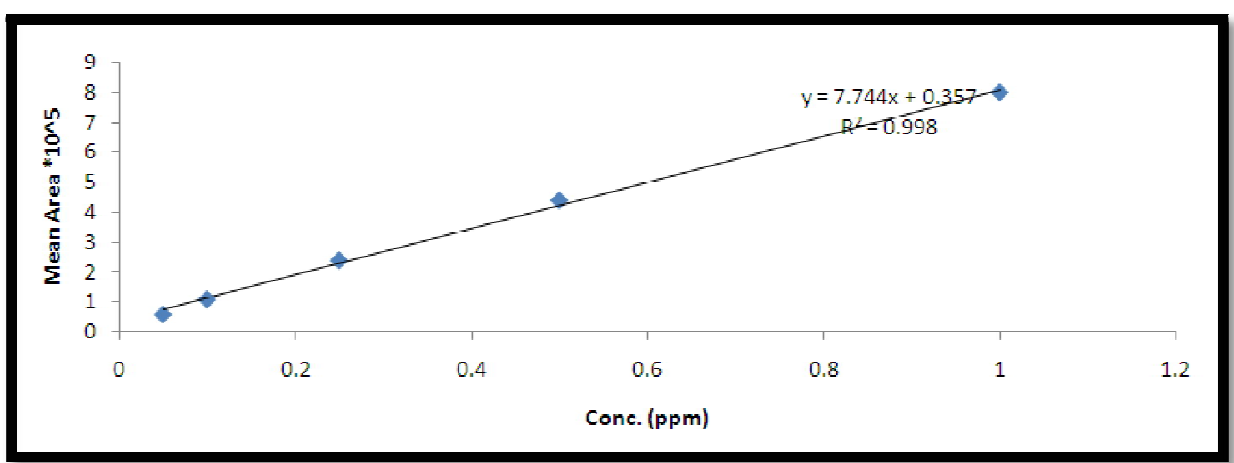

Figure 3: Calibration Curve for Diazinon Standard

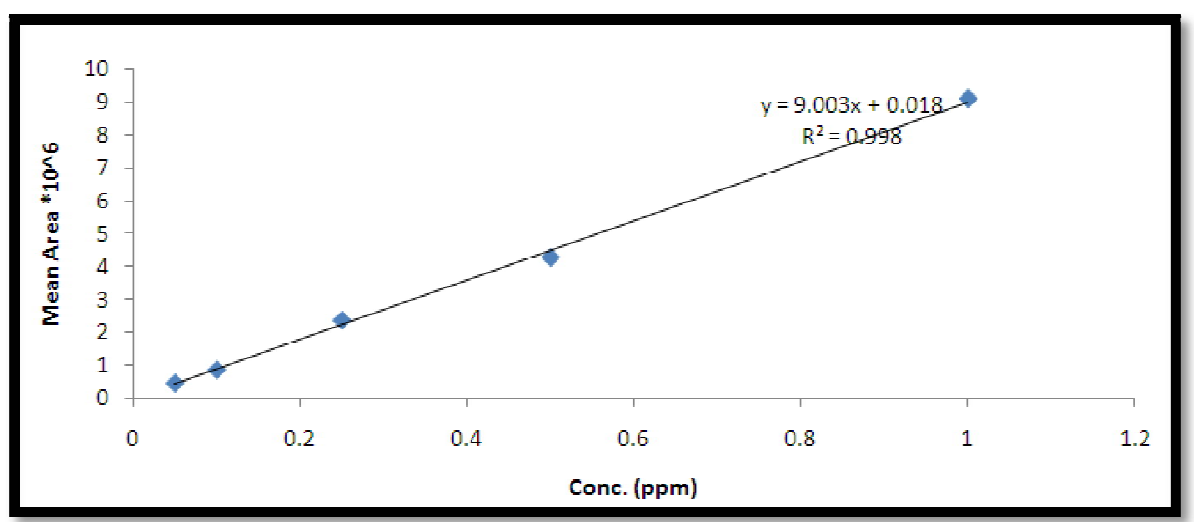

Figure 4: Calibration Curve for Carbaryl Standard 


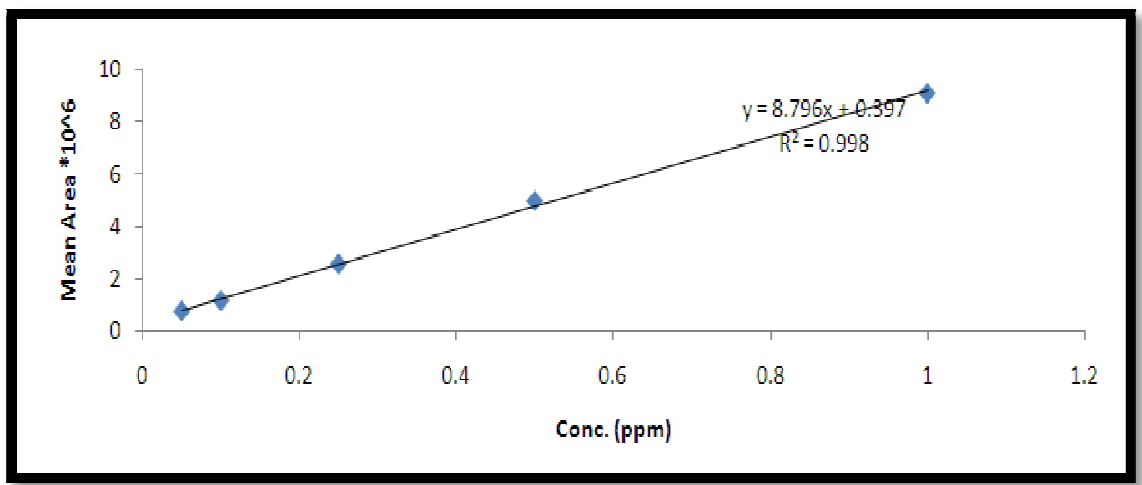

Figure 5: Calibration Curve for Malathion Standard

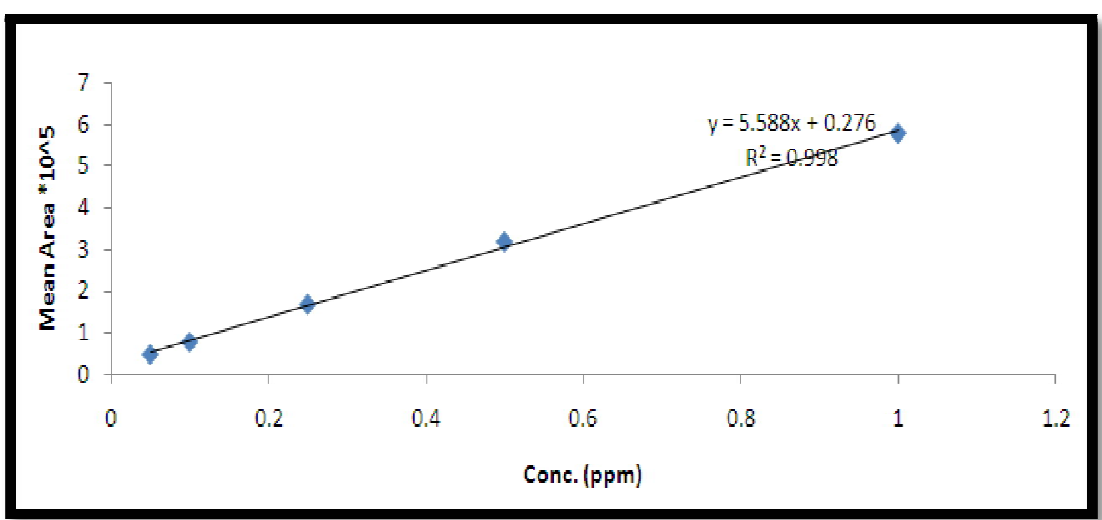

Figure 6: Calibration Curve for Chlorpyrifosstandard

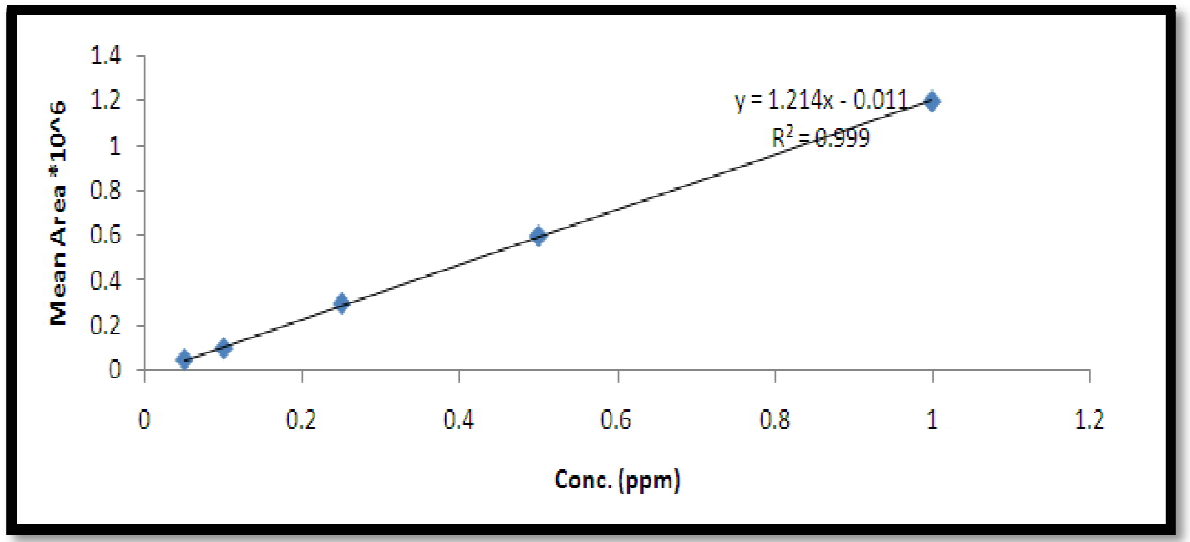

Figure 7: Calibration Curve for Ethionstandard

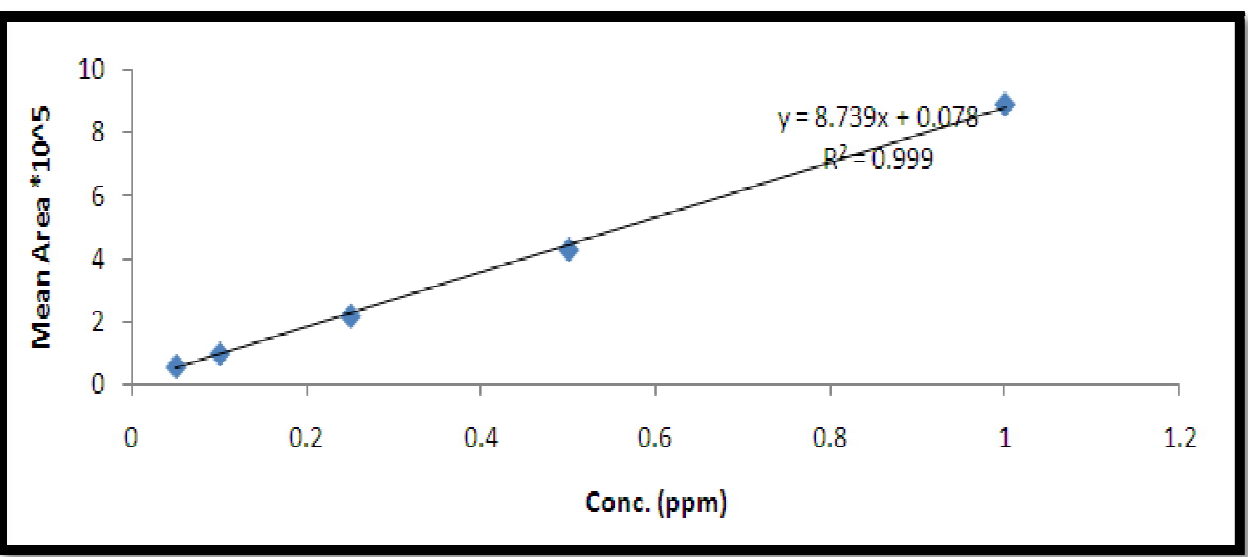

Figure 8: Calibration Curve for Carbofenthion standard 


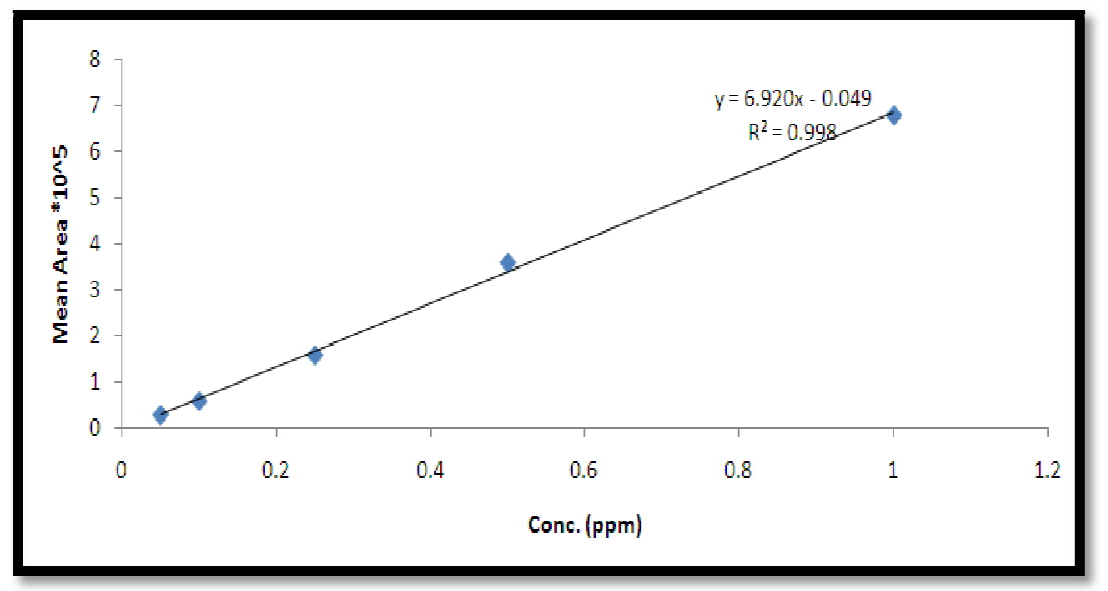

Figure 9: Calibration Curve for Azinphos-Methyl Standard

\subsection{Extraction and Clean-Up of Samples}

Homogenized samples $(15 \mathrm{~g})$ were weighted into a $50 \mathrm{~cm}^{3}$ polytetrafluoroethylene ethylene (PTFE) tube and 15 $\mathrm{cm}^{3}$ of acetonitrile containing $1 \%$ acetic acid (v/v) was added. Then $6 \mathrm{~g} \mathrm{MgSO}_{4}$ and 2.5 sodium acetate trihydrate (equivalent to $1.5 \mathrm{~g}$ of anhydrous form) was added and the sample shaken forcefully for 4 min and kept in ice bath. The samples were then centrifuged at 4000rpm for 5 min and $6 \mathrm{~cm}^{3}$ of the supernatant transferred to a $15 \mathrm{~cm}^{3}$ PTFE tube to which $900 \mathrm{mg} \mathrm{MgSO}_{4}$ and $300 \mathrm{mg}$ PSA was added. The extract would be shaken using a vortex mixer for 20s and centrifuged at 4000rpm again $5 \mathrm{~min}$, approximately $2 \mathrm{~cm}^{3}$ of the supernatant was taken in a vial. This extract was evaporated to dryness under a stream of nitrogen and reconstituted in n-hexane in auto sampler tube for the GC MS/ Analysis. (AOAC, Official Method 2007.01).

\section{Gas - Chromatography - Mass Spectrometry Analysis of the Samples}

The samples (vegetables, fruits, water and soils) were analysed using the Shimadzu QP 2010 GC/ MS equipped with chemstation software (GC 2071, Rev, A. 06.01). The primary capillary column for separation of pesticides was RTX-5 (Restek, $30 \mathrm{~m} \times 250 \mu \mathrm{m} \times 0.25 \mu \mathrm{m}$ ) (Dem etal.,2007). The carrier gas was helium, with a constant column flow rate of 1.1 $\mathrm{ml} / \mathrm{min}$ and the detector make up gas was nitrogen at a flow rate of $60 \mathrm{ml} / \mathrm{min}$. The samples were injected in the spitless mode with the purge flow rate to split vent set at $35 \mathrm{ml} / \mathrm{min}$ at $1 \mathrm{~min}$ and pressure at $15 \mathrm{psi}$ and total flow at $39 \mathrm{ml} / \mathrm{min}$. The injector temperature $250^{\circ} \mathrm{C}$ (RTX -5 injections) and the detector temperature programs was $350^{\circ} \mathrm{C}$. The temperature program on the TRX -5 capillary columns are as follows: $90^{\circ} \mathrm{C}$ for $0.00 \mathrm{~min}, 30^{\circ} \mathrm{C} / \mathrm{min}$ to $190{ }^{\circ} \mathrm{C}$ held for $20 \mathrm{~min}, 20^{\circ} \mathrm{C}$ / min to $275{ }^{\circ} \mathrm{C}$ held for $10 \mathrm{~min}$. For confirmation runs, the temperature program on the RTX -35 columns are as follows: $100{ }^{\circ} \mathrm{C}$ for $2.0 \mathrm{~min}, 15^{\circ} \mathrm{C} / \mathrm{min}$ to $160^{\circ} \mathrm{C}, 5^{\circ} \mathrm{C} / \mathrm{min}$ to $270{ }^{\circ} \mathrm{C}$ held for $5 \mathrm{~min}$.

\section{Identification and Quantification}

The identification of the compound was accomplished by comparing the retention times and mass spectra of analytes in samples to those of reference standards run at the same condition with the samples. Likewise, the concentrations of the pesticides were determined by interpolation of the relative peak areas for each pesticide compared with those of the standard peak.

\section{Results and Discussion}

The Table 1shows the detected pesticide organochlorine pesticide residues in fruits and vegetables with their mean concentrations while Table 5.2 presents the validated parameters of the organophosphorus and carbamate pesticides.

From the Table 5.1, the mean concentration of the organophosphorus pesticide residues in spinach ranged from $0.005 \mathrm{mg} / \mathrm{kg}$ in azinphos-methyl to $0.153 \mathrm{mg} / \mathrm{kg}$ in malathion while only carbofenthion, a carbamate was detected with a value of $0.064 \mathrm{mg} / \mathrm{kg}$ which is below the Codex Alimentarius limit of $0.50 \mathrm{mg} / \mathrm{kg}$.The residual dichlorvos was only detected in the spinach with value below MRLs, but, generally, the residual organophosphorus and carbamatepesticide in spinach currently does not constitute any hazard in Dagachi - Galma. However, Good Agricultural practice (GAP) must be emphasized to reduce build-up of organophosphorus in spinach in Dagachi to avoid the negative health implications of the pesticidesespecially the malathion which has been banned by NAFDAC in 2008. Residues of diazinon and mevinfos detected were found exceeding the MRLs in carrot and sorrel respectively with values $0.061 \mathrm{mg} / \mathrm{kg}$ and $0.026 \mathrm{mg} / \mathrm{kg}$. Also, mevinfos in tomatoes was above the MRLs with a value of $0.027 \mathrm{mg} / \mathrm{kg}$. Also, carbaryl were detected in carrot, sorrel, and tomatoes to be below the MRLs with values of $0.003 \mathrm{mg} / \mathrm{kg}, 0.002 \mathrm{mg} / \mathrm{kg}$ and $0.003 \mathrm{mg} / \mathrm{kg}$ respectively. All the detected chlorpyrifos in the samples were to be below the MRLs, however, chlorpyrifos is moderately toxic to humans and chronic exposure has been linked toneurological effects, developmental disorders, and autoimmune disorders. Exposure during pregnancy retards the mental development of children, and most use in homes has been banned since 2001 in the United States (Muller and Franz, 2000). Dichlorvos was not detected in all the analysed samples except in carrot with a value of $0.049 \mathrm{mg} / \mathrm{kg}$. Because dichlorvos degrades fairly rapidly so, it is not generally found as a residue on food (Fraser et al. 1989). Dichlorvos is absorbed through all routes of exposure and damages DNA of insects (Espeland et al. 2010). Dichlorvos can inhibit cholinesterase levels in humans which may lead to short- or longer-term neurotoxic effects. Since it 
is an acetyl cholinesterase inhibitor, its overdose symptoms in humans are weakness, headache, tightness in chest, blurred vision, salivation, sweating, nausea, vomiting, diarrhoea, and abdominal cramps (Maryse 2010).

Although, OPs pesticide residues in the analyzed samples do not generally constitute a health hazard, the detection of residual of ethion and malathion above the MRL when consumed frequently may lead to diseases associated with OPs pesticides such as neurological disorders, cancer, skin irritation, kidney disorders and associated health problems Pesticides can accumulate in the tissues of organisms as they are not easily soluble (Wang et al., 2011).Generally, most residues detected in all the samples were below the Codex FAO/WHO 1986 recommended MRL. Nevertheless, continuous consumption of food products even with moderate pesticide contamination may have negative consequences on human health in the long term (Savage et al., 1988).

From Table 5.2, the correlation coefficient $\left(\mathrm{r}^{2}\right)$ of the calibration curve was not less than 0.990 for the least squares of the analysed organophosphorus pesticides. The linearity of the methods was evaluated, different calibration standards of the pesticides were analysed by GC-MS and the response were recorded. A plot of the peak areas of the pesticides versus concentrations (in ppm) with $\mathrm{r}^{2}$ greater than 0.990 as shown in Table 3.1 were obtained. The $\mathrm{r}^{2}$ was found to be in the range of 0.991 to1.000, indicating that these pesticides can be determined in the sample at wide concentration range as they are even higher than 0.999 .

\section{Conclusion}

This study investigated the levels of organ phosphorus and carbamate pesticide residues in spinach, carrot, sorrel and tomatoes grown along River Galma at Dagachi area in Zaria. The results indicated that majority of the samples were contaminated with pesticide residues, with concentration above the MRL. From the public health perspective, some of the residues may pose a potential health risk to consumers. Therefore, to reduce this risk, sensitization of farmers to better pesticide safety practices and the need for continuous pesticide residue monitoring is highly recommended. Finally, there is a need for the relevant agency to strictly control the importation, sale, use and disposal of these toxic chemicals.

\begin{tabular}{|c|c|c|c|c|c|c|c|c|c|c|c|}
\hline \multicolumn{4}{|c|}{ S/n Samples dichlorvos mevinfos } & \multirow{2}{*}{$\begin{array}{l}\text { diazinon } \\
0.043 \pm 0.007\end{array}$} & \multirow{2}{*}{$\frac{\text { carbaryl }}{\text { ND }}$} & \multirow{2}{*}{$\begin{array}{l}\text { malathion } \\
0.153 \pm 0.143\end{array}$} & \multirow{2}{*}{$\begin{array}{c}\text { chlorpyrifos } \\
0.099 \pm 0.081\end{array}$} & \multirow{2}{*}{$\begin{array}{l}\text { ethion ca } \\
0.038 \pm 0.001\end{array}$} & \multirow{2}{*}{$\begin{array}{c}\text { carbofenthion } \\
0.064 \pm 0.001\end{array}$} & \multirow{2}{*}{$\frac{\mid \text { Isofenphos a }}{\text { ND }}$} & \multirow{2}{*}{$\begin{array}{c}\text { azinphos- methyl } \\
0.005 \pm 0.001\end{array}$} \\
\hline 1 & Spinach & ND & $0.030 \pm 0.002$ & & & & & & & & \\
\hline 2 & Carrot & $0.049 \pm 0.001$ & ND & $0.061 * \pm 0.004$ & $0.003 \pm 0.001$ & $0.522^{*} \pm 0.503$ & $0.274 \pm 0.136$ & $0.192 \pm 0.001$ & ND & ND & $0.006 \pm 0.001$ \\
\hline 3 & Sorrel & ND & $.026^{*} \pm 0.001$ & ND & $0.002 \pm 0.001$ & $0.078 \pm 0.001$ & $0.004 \pm 0.001$ & ND & ND & $0.022^{*} \pm 0.001$ & $0.013 \pm 0.0 .001$ \\
\hline 4 & Tomatos & es ND & $.027 * \pm 0.001$ & ND & $0.003 \pm 0.001$ & $0.057 \pm 0.040$ & $0.122 \pm 0.109$ & $0.004 \pm 0.001$ & 1 ND & ND & $0.006 \pm 0.001$ \\
\hline
\end{tabular}

Table 1: Mean Concentration (Mg/ Kg) Of Organosphorus and Carbamate Pesticide Residues in the Fruits and Vegetables at Dagachi Farm Alongriver Galma $\mathrm{ND}=$ Not Detected $*>\mathrm{MRL}$

\begin{tabular}{|c|c|c|c|c|}
\hline Pesticide & Linear Range & $\mathbf{R}^{\mathbf{2}}$ & LOD (ppm) & LOQ (ppm) \\
\hline Dichlorvos & $0.05-1.00$ & 0.997 & 0.114 & 0.049 \\
\hline Mevinfos & $0.05-1.00$ & 0.997 & 0.010 & 0.034 \\
\hline Dimethoate & $0.05-1.00$ & 0.998 & 0.018 & 0.061 \\
\hline Diazinon & $0.05-1.00$ & 0.998 & 0.010 & 0.034 \\
\hline Pirimicarb & $0.05-1.00$ & 0.998 & 0.063 & 0.209 \\
\hline Phosphamidon & $0.05-1.00$ & 0.997 & 0.015 & 0.050 \\
\hline Diclofenthion & $0.05-1.00$ & 0.996 & 0.012 & 0.041 \\
\hline Metribuzin & $0.05-1.00$ & 0.994 & 0.030 & 0.101 \\
\hline Carbaryl & $0.05-1.00$ & 0.998 & 0.008 & 0.029 \\
\hline Pirimiphos -methyl & $0.05-1.00$ & 0.999 & 0.014 & 0.046 \\
\hline Malathion & $0.05-1.00$ & 0.998 & 0.010 & 0.030 \\
\hline Chlorpyrifos & $0.05-1.00$ & 0.998 & 0.014 & 0.047 \\
\hline Fenthion & $0.05-1.00$ & 1.000 & 0.010 & 0.032 \\
\hline Isofenphos & $0.05-1.00$ & 0.997 & 0.071 & 0.236 \\
\hline Fenamiphos & $0.05-1.00$ & 0.998 & 0.015 & 0.049 \\
\hline Ethion & $0.05-1.00$ & 0.999 & 0.064 & 0.240 \\
\hline pcB -153 & $0.05-1.00$ & 0.000 & & \\
\hline Carbofenothion & $0.05-1.00$ & 0.999 & 0.009 & 0.030 \\
\hline Triphenyl phosphate & $0.05-1.00$ & 0.000 & & \\
\hline Azinphos -methyl & $0.05-1.00$ & 0.998 & 0.011 & 0.038 \\
\hline
\end{tabular}

Table 2: Parameters for Validation of Organ phosphorus Pesticides

LOD - Limit of Detection $=3 S_{a} / b$

LOQ - Limit of Quantification $=10 \mathrm{~S}_{\mathrm{a}} / \mathrm{b}$

$\mathrm{R}^{2}$ - Correlation Coefficient 
$\mathrm{S}_{\mathrm{a}}=$ standard deviation of the response (which is estimated as the standard deviation of the y-intercept of the least square regression line, $\mathrm{R}^{2}$ ) (Garyd, 2008) and

$\mathrm{b}=$ slope of the calibration curve.

\section{References}

i. Al- Saleh, I.A. (1994). Pesticides a review article.J. Environ pathol. Toxical. On col. Vol.3

ii. Applications. Toronto: Wiley-VCH. p. 541.

iii. Association of Analytical Communities (AOAC) official method 2007.01.

iv. Cheng, C.L. and Bersamira, K.V. (1994), Pesticides: It's hazardous effects on the benguet

v. Conacher, H.B.S and Mes, J. (1993). Assessment of human exposure to chemical contaminants in Foods. Food Addit Contam. 10, 5-15.

vi. Espeland, M., Irestedt, M., Johanson, K.A., Åkerlund, M., Bergh, J.E. and Källersjö, M. (2010), Dichlorvos exposure impedes extraction and amplification of DNA from insects in museum collections. Frontiers in Zoology, 7: 2.

vii. Fan MA, Alexeeff GV (1999). Public Health Goal for Endrin in Drinking Water. Office of Environment Health and Hazard Assessment. Environmental Protection Agency, $\quad$ California, 5-6.

viii. FAO/WHO (1986) Codex Maximum Limits For Pesticides residues. 2nd ed. Rome, Food and Agriculture Organization of the United Nations Codex Alimentarius Commission (CAC [Vol III).

ix. farmers and the environment, Unique Printing Press, Baguio City, Philippines.

x. Fernandez - Alba, A,R. and Garcia-Reyes, J,F. (2008). Large-Scale mull-residue methods for pesticides and their degradation products in food by advanced LC - MS. Trac-Trend. Anal.Chem. 27(11):973-990.

xi. Fraser, J.P., Duncan, G. and Tomlison, J. (1989). Effects of a cholinesterase Inhibitor on salmonid lens, a possible cause for the Increased Incidence of cateract in salmon salmo salar. Exp. Eye Res. 49, 293-98.

xii. Guilhermino, L., Soares A., Tinoco-Ojanguren R. and Osten J (2004). Effect of pesticide exposure on acetylcholinesterase activity in subsistence farmers from Campeche, Mexico.Archives of Environmental Health: 3: $1-30$

xiii. Maryse, F.B., David, C.B., Robert, O.W. and Marc, G.W. (2010), Attention-Deficit/ Hyperactivity Disorder and Urinary Metabolites of Organophosphate Pesticides, Pediatrics 125:6 e1270-e1277

xiv. $\quad$ Muller, Franz, ed. (2000). Agrochemicals: Composition, Production, Toxicology, no. 3 pp 151- 161.

xv. Podolska M. and Napierska D.Acetylcholinesterase activity inhosts (herring Clupeaharengus) and parasites (Anisakis simplex larvae)from the southern Baltic.ICES (International Council for the Explorationn of the Sea) Journal of Marine Science. 2006; 63(1): 161-168.

xvi. UNEP (2004). Childhood pesticide poisoning information for advocacy and action. Prepared for the United Nations Environment Programme (UNEP). United Nations environment programme (UNEP chemicals) with the assistance of UNEP's information unit for conventions. May, 2004.

xvii. Van Enden, H.F. (1989). Pest control 2nd Cambridge University Press, London. PP 1-4.

xviii. Walter, J.C. (2009). Chlorinated pesticides threats to health and importance of detection".Environmental Medicine. $14(4): 347-59$. 